and larger than that formerly obtained by Puluj from transpiration-experiments with capillary tubes $\left(\frac{2}{3}\right)$. The exponent for hydrogen is somewhat smaller than that for air. Not a little interesting is the remarkably large exponent for carbonic acid, in which the friction appears nearly to follow the law of temperature, to which Maxwell's new theory of gases leads (which, as is known, proceeds from the supposition of a repulsive action at a distance, inversely proportional to the fifth power of the distance of the molecules).

From these experiments it clearly appears that the friction does not, in all gases, vary with the temperature in the same way. The theory of gases must still undergo modification, in order to afford us a satisfactory explanation of this molecular process.

S. W.

\section{THE EARLY HISTORY OF MAGNETISM}

THE earliest references to the properties of the magnet occur in the annals of the Chinese nation, who used it as a means of guiding the wayfarer over the vast and trackless plains of Eastern Asia, long before it was applied to maritime purposes. To the Emperor Hoang-Ti, who lived 2,000 years before our era, is attributed the invention of a chariot, upon which stood an elevated figure pointing to the south, independently of any position of the chariot. Nearly ten centuries later, we find the learned Tcheou. Koung presenting and teaching the use of the tchi-nân. kiu, or chariot indicating the south, to some envoys from Youé-tchâng, a southern maritime province. The compass, or, as it is even now called in Chinese, $t c h i-n \hat{a} n$, appears to have been first used at sea by this remarkable nation about the third century of our era, during the Tsin dynasty.

When the compass became known in Europe is disputed; Gilbert refers its introduction to Marco Polo about 1260,1 but it is probable that earlier accounts of it wero brought from the East by the Crusaders, an accurate description of it occurring in a poem entitled "La Bible," written by the minstrel Guiot de Provence about the yeat 119o. A Latin letter ascribed to Peter Adsiger, 1269, preserved among the manuscripts of the uriversity of Leyden, contains the following remark on the declination of the needle:- "Take notice that the magnet, as well as the needle that has been touched by it, does not point exactly to the poles, but that part of it which is reckoned to point to the south declines a little to the west; and that part which looks towards the north in. clines as much to the east. The exact quantity of this declination I have found, after numerous experiments, to be five degrees."

The discovery of the dip of the needle is due to Robert Norman, a nautical instrument maker at Wapping, near Lond on, who is described by Gilbert as "a skilful sailor and ingenious artificer." He found that after being touched by a magnet the needie always appeared heavier at its northern end, and making an instrument to determine the greatest angle formed with the horizon, he observed the inclination in 1576 to be $71^{\circ} 50^{\prime}$.

In the early part of the following century, the variation of the declination was clearly ascertained, and was attributed by Bond, a teacher of navigation in London, to the motion of two magnetic poles.

In the year 1600 was published the celebrated treatise "De Magnete," by Gilbert of Colchester, who was pronounced by his great contemporary Galileo, to be "great to a degree that might be envied." Gilbert regarded our globe as a great magnet, and its centre as the centre of the magnetir. motions of the earth. Variation he defines to be the arc intersected between the point where the meridian of the place cuts the horizon, and that point to

I "Scientia Neuticæ pyxiduls traducta videtur in Italiam per Pauluw Venetum, qui circa anmum M.CCLX. apud Chinas artem pyxidis didicet. De Magnete, p. 4. which the magnetic needle looks ; the length of this arc varying with the place of observation. He states that from the coast of Guinea to the Canary Islands, and thence throughout Spain, Gaul, England, Germany, and Norway, the magnetic needle turns towards the east, that on the opposite shores of North America it turns to the west, whilst near to the Azores it points exactly north and south; nor does he fail to observe that from the north of Brazil, along the coast of South America to the Straits of Magellan, the southern end of the needle points west of the true meridian. He rejects the vulgar opinions of variation depending upon magnetic mountains or magnetic rocks, upon the poles of the zodiac, or the positions of certain fixed stars, but ascribes it in some measure to the configuration of sea and land on the surface of the earth; chiefly, however, to irregularities in what he terms the magnetic globe and true earth, which he conceives to be more considerable under the continents than below the depths of the ocean. He devotes the fifth book of his work to a full account of the dip of the needle, termed by him declination, with a minute description of the instruments used in its measurement.

Descartes attributes variation to the irregularities of the earth's surface, considering magnetic attraction strongest wherever iron and loadstone are most abundant. To account for the variation of the compass, he asserts that the amount of iron in certain localities constantly changes, partly because man draws it from one place to transport it to another, and partly because new iron is formed in some districts where there was none before, whilst irr others old iron becomes corrupted and disappears entirely. To explain his theory of magnetism it is necessary to state briefly the hypothesis he formed respecting matter in general, an hypothesis for which he does not claim absolute truth, but one from which deductions may be made in conformity with experience. The universe he supposer was formed originally of one uniform materiai, divided into equal parts having equal movements. These movements he considered to be twofold, each part revolving on its own axis, and several together revolving round fixed centres, and thus forming distinct vortices. As he deemed no void possible, it followed that these parts being equal, could not at first have been round, but might eventually become so, their angles as they met together being rubbed off and the intervening spaces filled with the dust or débris.

Descartes considered these two forms of matter as two elements of the universe, the first consisting of the débris and the second of the little spheres. The less agitated parts of the first move chiefly in straight lines from the poles to the centre of each vortex, and in passing through the triangular spaces often left between contiguous balls of the second element, they assume the form of fluted, spiral columns. On the disposition of their channels the force of the magnet principally depends. His third element is formed by the union of the less subtile matter of the first, including the fluted columns. From the centrifugal force of the round parts a central space is left within each vortex, composed purely of matter of the first element ; this Descartes supposed to form an extremely subtile body, such as he conceived the fixed stars to be, and even considered that the earth formerly occupied such a centre till the less subtile matter collecting on its surface changed into that of the third element, and thus formed clouds and other obscure bodies. As each new layer was added, the force of the containing vortex diminished, and more matter escaped into the surrounding vortices than returned to occupy its place ; finally, the earth, enveloped in its atmosphere, descended to the position it now occupies in the powerful vortex around the sun. He divides it into three regions, the lowest consisting entirely of matter of the first element ; the middle, of an opaque solid body containing passages sufficiently large to admit the fluted columns of the first, but not the spheres of the second element, 
whilst the upper is formed of a confused mass of matter which belongs chiefly to the third element, but is interspersed with the round balls of the second. The passages in the intermediate region he conceives to be so grooved that the fluted columns entering from one side cannot return again by the same passages, but when opposed in their straight course are forced back through the air or upper portions of the earth to those openings by which they entered, whilst those from the other side make similar circuits. He considers that magnets contain passages the same as those first mentioned, and such is the inclination of the fluted columns to enter these passages, that even if the poles are not turned to receive them they will push aside all opposing particles, till, if not restrained by still stronger bodies, the magnets are forced to assume those positions in which their poles point oppositely to those of the eart h. ${ }^{1}$. Juch is the hypothesis of Descartes, ingenious rather than plausible, and interesting chiefly as exhibiting the speculative mind of its author.

In 1683 the celebrated Halley presented a paper of great importance to the Royal Society of London, entitled "A Theory of the Variation of the Magnetical Compass." In this communication he states that the "deflection of the magnetical needle from the true meridian is of that great concernment in the art of navigation, that the neglect thereof does little less than render useless one of the noblest inventions mankind ever yet attained to," and gives as the result of "many close thoughts" the following explanation of the variation of the compass. "The whole globe of the earth is one great magnet, having four magnetical poles or points of attraction, near each pole of the equator two ; and in those parts of the world which lie near adjacent to any one of those magnetical poles, the needle is governed thereby, the nearest pole being always predominant over the more remote." He remarks that the positions of these poles cannot as yet be exactly determined from want of sufficient data, but conjectures that the magnetic pole which principally governs the variations in Europe, Tartary, and the North Sea is about $7^{\circ}$ from the north pole of the earth, and in the meridian of the Land's End, whilst the magnetic pole which influences the needle in North America, and in the Atlantic and Pacific Oceans, from the Azores westward to Japan, is $15^{\circ}$ from the north pole, and in a meridian passing through the middle of California. The variation in the south of Africa, in Arabia, Persia, India, and from the Cape of Good Hope, over the Indian Ocean to the middle of the South Pacific, is ruled by the most powerful of all these magnetic poles, which is situated $20^{\circ}$ from the south pole of the earth, and in a meridian passing through the island of Celebes; in the remainder of the South Pacific Ocean, in South America and the greater part of the South Atlantic Ocean, it is governed by a magnetic pole $16^{\circ}$ from the south pole, in a meridian $20^{\circ}$ west of the Straits of Magellan. On this hypothesis Halley explains the variation observed in different places, and among others cites the two following instances. On the coast of America, about Virginia, New England, and Newfoundland, the variation was found to be west, being above $20^{\circ}$ in Newfoundland, $30^{\circ}$ in Hudson Strait, and $57^{\circ}$ in Baffin's Bay. On the coast of Brazil, on the contrary, it was found to be east, being $12^{\circ}$ at Cape Frio, and increasing to $20^{\circ}{ }^{\circ}$ at the Rio de la Plata, thence decreasing towards the Straits of Magellan. Thus, almost in the same geographical meridian, we find the needle at one place pointing nearly $30^{\circ}$ west, at another $20^{\frac{1}{2}}$ east ; this is explained by the north end of the needle in Hudson Strait being chiefly attracted by the North American magnetic pole, whilst at the mouth of the Rio de la Plata the south end is attracted by the south magnetic pole, situated west of the Straits of Magellan.

${ }^{x}$ Descartes designates the south pole of the magnet that which turns to the north pole of the earth, and"the north pole of the magnet that which turns to the south pole of the earth.
Sailing north-west from St. Helena to the equator, the variation is always in the same direction, and slightly east. Here the South American is the chief governing pole, but its power is opposed by the attraction of the North American and Asian south poles; the balance as you recede from the latter being maintained by approach to the formier.

Nine years later Halley made another communication to the Royal Soceity, in which he endeavoured to meet two difficulties he had always felt in his former explana. tion; one, that no magnet he had ever seen or heard of had more than two opposite poles; the other, that these poles were not, at least all of them, fixed in the earth, but slowly changed their positions. The following observations are cited by Halley in proof of the motion of the magnetic system. At London, in 1580 , the variation was $11^{\circ} 15^{\prime}$, east; in 1622 it was $6^{\circ}$ east, in 1634 it was $4^{\circ} 5^{\prime}$ east, and in 1657 there was no variation; whilst in 1672 , it was $2^{\circ} 30^{\prime}$ west; and in $1692,6^{\circ}$ west. At Paris the variation was $8^{\circ}$ or $9^{\circ}$ east in $155^{\circ}, 3^{\circ}$ east in $1640,0^{\circ}$ in 1666 , and $2^{\circ} 30^{\prime}$ west in 1681 . At Cape Comorin it was $14^{\circ} 20^{\prime}$ west in $1620,8^{\circ} 48^{\prime}$ west in $\mathrm{r} 680$, and $7^{\circ} 30^{\prime}$ west in 1688 . Halley considered the external parts of our earth as a shell, separated by a fluid medium from a nucleus or inner globe, which had its centre of gravity fixed and immovable in the common centre of the earth, but which rotated round its axis a little slower than the superficial portions of the earth. The nucleus and exterior shell he regarded as two distinct magnets, having magnetic poles not coincident with the geographical poles of the earth. The change observed in Hudson's Bay being much less than that observed in Europe, Halley concluded that the North American pole was fixed, while the European one was movable; and, from a similar observation on the coast of Java, he considered the Asian south pole as fixed, and the pole west of the Straits of Magellan to be in motion. The fixed poles he regarded as those of the external shell, and the movable those of the inner nucleus. Of these latter, the cne placed by him in the meridian of the Land's End was ascertained, in the present century, to have moved to Siberia, in $120^{\circ}$ east Iong., and that placed by him $20^{\circ}$ from the Straits of Magellan to have moved between $30^{\circ}$ and $40^{\circ}$ west of this position while those poles regarded by Halley as fixed were found but slightly altered in position since his time. It is extremely interesting to find that not only modern observations of declination, but also those of dip and magnetic intensity, have received their best explanation on the assumption of four magnetic poles. Much, however, that is mysterious remains unsolved, and Halley's remarkable words may even now with truth be quoted: "Whether these magnetical poles move altogether witb one motion or with several; whether equally or unequally; whether circular or libratory; if circular about what centre. if libratory after what manner, are secrets as yet utterly unknown to mankind, and are reserved for the industry of future ages."

K.

\section{THE POTATO DISEASE}

$\mathrm{N}$ the Fournal of the Royal Agricultural Society of Englanci, Second Series, vol. xii., Part I., No. xxiii., 1876 , Prof. A. De Bary of the University of Strasburg has published a paper entitled "Researches into the Nature of the Potato Fungus."

De Bary's essay treats of the Peronosporeæ, Artotrogus (in its plain and echinulate forms) and Pythium. These fungi are described by De Bary as four distinct plants, whilst $I$, in common with several other observers, believe the first three (if indeed not all four) to be mere conditions of one and the same fungus, viz., the Peronospora infestans of Dr. Montagne. In replying to De Bary's remarks it will be convenient (especially as the potatofungus appears to be somewhat imperfectly understood), 